\title{
UNILATERAL PAGET'S DISEASE IN YOUNG ADULT: A CASE REPORT
}

Sarah B. D. Carrijo', Lucas F. S. Pereira', Larissa F. Almeida', Jordana M. Oliveira', Cesar A. S. T. Vilanova-Costa², Antonio M. T. C. Silva'

'Escola de Ciências Médicas, Farmacêuticas e Biomédicas, Pontifícia Universidade Católica de Goiás - Goiânia (GO), Brazil. 2Laboratório de Biologia Tumoral, Hospital Araújo Jorge, Associação de Combate ao Câncer em Goiás - Goiânia (GO), Brazil.

Introduction: Paget's disease (intraepidermal nipple carcinomatous cell migration from underlying breast carcinoma) is a rare form of breast cancer, occurring between 1 to $4 \%$ of patients at the age of 50-60 years. The lesion presents as an eczema-like modification of the nipple's appearance with characteristic melanic pigmentation. Objectives: To analyze the importance of an early diagnosis and medical follow-up in a case of Paget's disease with unusual presentation. Case Report: C.O.R, female, 35 years on March, 2018, noticed a brownish scaling spot on the left nipple, with no secretion, retraction or pruritus. Ultrasonography was performed, in which a nodule in the left breast was classified as BI-RADS3. After 3 months, a new ultrasonography was performed, obtaining the same result. In November 2018, with noticeable growth of the spot, onset of retraction, pain in stitches and greater desquamation, the main diagnostic hypothesis was eczema. Afterwards, a biopsy of the lesion was requested and Paget's disease was suggested. A mammography was requested and it did not show any changes. Histochemical examination confirmed Paget's disease, with an oncologic surgical indication. On December 2018, the nipple excision was performed, as well as a biopsy of the lump previously reported on ultrasonography, which was subsequently shown as grade 1 invasive cancer, BI-RADS6. On January 2019, a left mastectomy was performed, with removal of 2 axillary lymph nodes. To prevent the disease on the right breast, Tamoxifen was prescribed. Conclusion: The report shows the rarity of the case, which involves an unusual age of the disease manifestation. It is important to enable physicians to perform clinical investigation and early diagnosis for the best follow-up and prognosis of the patient, since it is a disease that is often asymptomatic and confused with benign disorders. 